\title{
Habitat Computing: Towards the Creation of Tech- Enabled Mexican Neighborhoods
}

\author{
Victor M. Gonzalez ${ }^{1}$, Luis A. Castro ${ }^{1}$, and Kenneth L. Kraemer ${ }^{2}$ \\ ${ }^{1}$ Manchester Business School, University of Manchester, United Kingdom \\ ${ }^{2}$ Paul Merage School of Business, University of California, Irvine, USA \\ \{vmgonz, luis.castro-quiroa\} @manchester.ac.uk, \\ kkraemer@uci.edu
}

\begin{abstract}
The use of personal computers and Internet at home is becoming more and more common in some developing countries such as Mexico, where affordable prices and credit plans have contributed to this trend. Undoubtedly, the presence of information technology in the households has effects in the life of families and their communities; however how beneficial these effects are depends on the way technology is contextualized to support domestic and community practices. Achieving a proper contextualization is the goal of what we call habitat computing. This paper presents the case of Real del Sol, a housing community in Mexico where an implementation of habitat computing is being developed. Houses are built with Internet access and personal computers as part of their basic infrastructure. We analyze here the role, usage and development of the Real del Sol community intranet, which is a key element on supporting the vision of the project.
\end{abstract}

Keywords: Community Intranets, Security cameras, Online Shopping.

\section{Introduction}

The use of personal computers and Internet at home is becoming more and more common in some developing countries such as Mexico, where affordable prices and credit plans have contributed to this trend. A study conducted by the Mexican Association of Internet, in 2005, revealed that about 20 million Mexicans had some form of internet access, from which $43 \%$ reported to have it at home [1]. According to Mexican Institute of Statistics, the growth of Internet access at home increased 20\% in 2005 with respect to the previous year [2]. These figures reflect a scenario where, without reaching the rates of penetration experienced in the developed world, the uptake of computer technology and internet access in Mexico is real and palpable. In parallel, in the last few years, Mexico has experienced a sustained investment to build housing complexes that are affordable, especially for low and middle-level income people. Through credit plans and mortgages, more people have been able to afford their own house. These two aspects do not reveal an idealistic scenario where both digital and housing divides have been eliminated; Mexico is far from that. Instead, we believe that they reveal a set of conditions where technologies are likely to impact the very conceptual bases of what we understand for homes and more generally neighborhoods; a vision that we refer here as habitat computing. 
This paper presents results of a study conducted to understand the practicalities of implementing a vision of habitat computing in a Mexican neighborhood. In the city of Tecamac, in Mexico, Real Paraiso Residencial, a housing company, in partnership with Conectha, an Internet Service Provider, built a residential complex (Real del Sol) consisting of about 2000 houses equipped with a personal computer and broadband internet access. The analysis presented here focuses on the characteristics of the community intranet technology and the usage of the computer and online services during the first year of use. Although we did find that the adoption and domestication of information technologies achieved in Tecamac is still minimum it was possible to identify the reasons for this, as well as many areas where further development is likely to produce a greater impact.

The rest of the paper is organized in the following way: Section 2 presents a definition of habitat computing and refers to previous studies to set the background and motivation for this study. Section 3 provides details about the case study and the research methodology. Section 4 presents the characteristics and services supported by the community intranet used in Real de Sol. Section 5 discusses the current state of technology usage at Real del Sol as well as our findings with regards to the main factors facilitating or preventing the uptake of the community intranet. Finally, section 6 closes the paper with some conclusions and discussion of results.

\section{Defining Habitat Computing and Related Studies}

Undoubtedly, the presence of information technology in the households has effects in the life of families and their neighborhoods; however how beneficial these effects are depends on the way technology is contextualized to support domestic and community practices. To contextualize, or domesticate, information technology means to integrate it to the household practices in a natural way [3]. This level and type of natural integration constitutes what we call habitat computing. Many communication technologies such as the telephone, television, or postal mail have achieved that level of integration, becoming constitutive elements defining what most of us consider being a home. Their constitutive nature can be seen on the way in which many domestic routines (e.g. season greetings cards preparation) and the very architecture of the household (e.g. TV rooms) have been shaped by their characteristics. Similarly, we believe that by adapting information technologies to support the practical and everyday needs of families and their housing communities we can materialize successful scenarios of habitat computing. Obviously, the challenge becomes to identify those needs, but more important to create solutions that respond to them in an unobtrusive, natural and simple way. Furthermore, we argue that fundamental and practical changes in household practices can be realized if instead of following paths leading to automation, assisted living and smart homes, designers take an approach that aims at supporting more 'down to earth' needs and, at the same time, assume that it will be for its sustained usage that information technology will find its way to become domesticated.

Many previous studies have been conducted within the context of information and communication technology usage at home and neighborhoods. Among them, the experiences of Blacksburg, Virginia in the US, gave clear indications that the 
adaptation of information technologies can give people at local neighborhoods new opportunities for social interaction, trade, information exchange, identity development and social cohesion [4]. Similarly, other studies have explored the uptake of computer and Internet at home and have identified benefits derived from their usage such as support on children education, cost savings in communication, increased opportunities for merchant comparison and shopping, as well as the new channels for entertainment and amusement [5]. Clearly, the uptake of computer technology at home is not exempt of challenges. A number of studies have reported that lacking critical mass, good quality content, and open participation, can prevent successful implementation of technologies supporting community neighborhoods [6-7]. Within the context of home, Venkatesh et al [5] reported that current computer technologies, being designed for individuals rather than families, cause problems and challenges in domestic settings, and that future designs should pay attention to the requirements for everyday living.

Following the line of studies on community networks [5-9] and home telematics [10], we believe that more investigation has to be conducted to expand our understanding of scenarios where information technology integration is the result of an orchestrated strategy to create habitat computing. This scenario is different to other where technology integration is a result of academic initiative or just a result of accidental circumstances. In scenarios that aim at promoting and implementing habitat computing, computers and Internet access are seen as part of the constitutive elements of the home and neighborhoods and therefore consider ubiquitous utilities like gas, water or electricity. We were motivated to understand such scenario as it was experienced in a housing complex in Mexico were designers took the perspective outlined above.

\section{Characteristics of the Study and Methodology}

At the end of February 2006, with the support of Real Paraiso Residencial and Conectha we conducted a set of ethnographic interviews with families living in or about to move to Real del Sol. A number of people were identified as likely to accept taking part in the study and then were contacted. Those voluntarily accepting where then scheduled for an interview.

A total of 34 individuals were interviewed covering 27 households averaging 3 members per family ( 87 individuals in total). Interviewees have a variety of occupations, from journalists to primary school teacher and from house keepers to tourist agents. The interviews were semi-structured and covered a set of topics including the factors motivating the purchase of the houses, the experience of moving in, the relationships with the neighbors and the rest of the community, their use of the technology to support domestic practices as well as perspectives on how to make the technology more useful. Each interview lasted an average of 45 minutes and was conducted in their houses. Just in two cases interviews were conducted at Conectha's offices, as the informants had not yet moved to their properties by the time of the interviews. The interviews were complemented with a number of observations of the community and informal interviews with staff from both Conectha and Real Paraiso Residencial, as well as with people from the Ojo de Agua community (not living at Real del Sol), including taxi drivers, shop 
owners and security staff. The data collected were then analyzed using a comparative approach aiming at identifying patterns among the responses and producing an integrated set of findings.

\section{Habitat Computing: The Case of Real del Sol}

At the beginning of 2005, Real Paraiso Residencial and Conectha started the construction of their first housing complex guided by a concept called "Habitat of Seventh Generation" o G7 Habitat. They defined G7 Habitat as a household concept that emerges from sixth previous generations experienced by the domestic household. Under this design concept, Information and Communications Technologies (ICTs) play not just a strategic role, but one where they are intrinsically linked and embedded to the basic idea of a household. Upfront, they envisioned houses where Internet access was one more of the core utilities, as opposed to an optional service. They aimed at having all houses with at least one personal computer connected to the Internet and with access to a set of local services around the G7 Habitat concept. To achieve this, Conectha designed and built a community intranet portal. This section describes the characteristics of that intranet.

\subsection{The Houses and the Community}

Real del Sol housing development is located in the city of Tecámac, in the State of Mexico. Although Tecámac is not part of the metropolitan area of Mexico City, it is close enough as to allow a reasonable commute to the city (approximately an hour trip, with good traffic conditions). The majority of residents work in Mexico City.

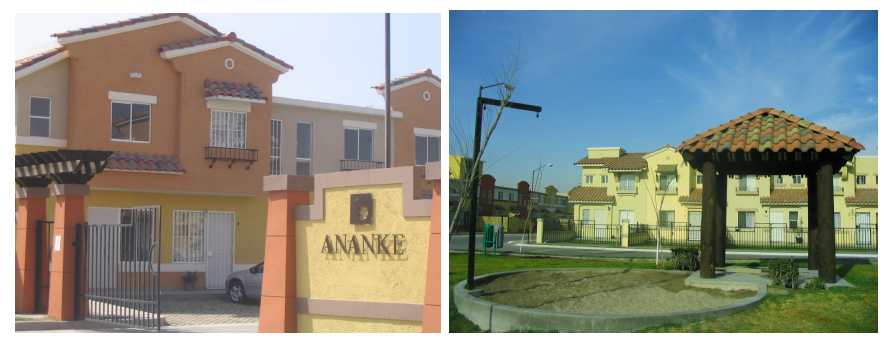

Fig. 1. A typical house in Real del Sol (Privada Ananke); view of common areas

The design of the houses followed a Californian style that aims at distinguishing each property: No two adjacent houses have the same designs emphasizing individuality and diversity. Compared with similar complexes within the same range of prices, the housing development at Real de Sol, is more aesthetic and well integrated. The development counts with two small parks, basketball courts, a primary school, a kindergarten, and other communal areas. To facilitate organization, the development is organized in privadas, groups of ten or twenty houses that are separated of the rest with gates. People in the privadas share some green areas and services (trash bins sections). Figure 1 shows a picture of a house in Real del Sol and 
a partial view of one of the communal gardens. Each house counts with all standard services (water, electricity, gas), including Internet access thorough a wireless network that allows speeds up to $384 \mathrm{Kbps}$. Some of the houses also include a personal computer for free or it is offered by Conectha at preferential prices. The houses are about 30 square meters or more, with 2-4 bedrooms and a range of prices starting at $\$ 25,000$. Most owners purchased the properties through credit plans and mortgages offered by private and government agencies.

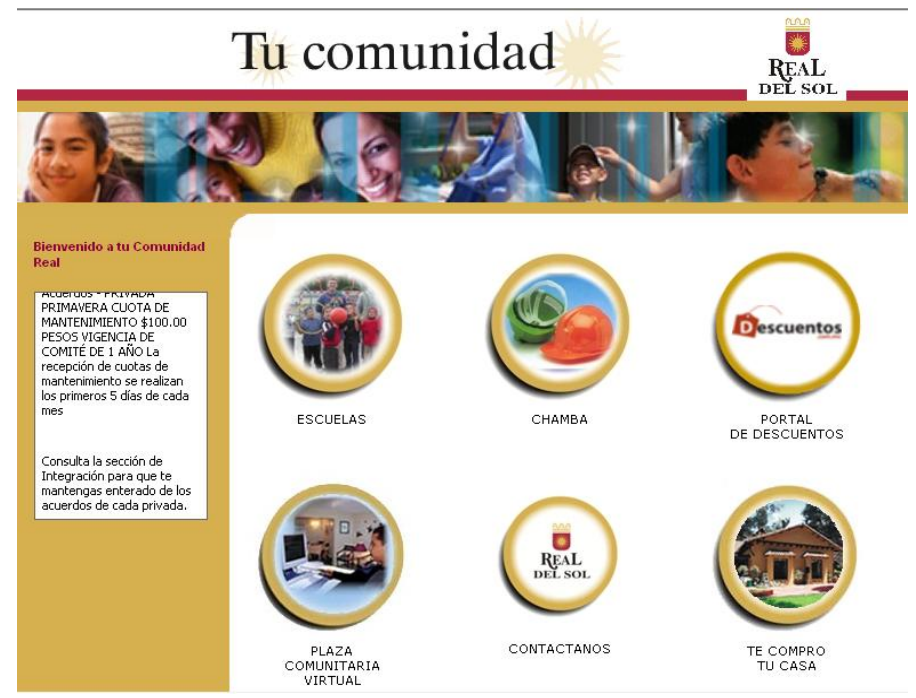

Fig. 2. Community Intranet in Real del Sol

\subsection{Real del Sol Intranet and E-Mail}

Through their home computers, neighbors of Real del Sol have access to a set of services in the community intranet designed by Conectha. The intranet is operated and maintained by Conectha's staff, and there is not direct way for neighbors to modify their contents. In spite of that, neighbors are encouraged to provide content of common interest that then is published by the webmaster. Figure 2 shows a screenshot of the Intranet.

Each resident is given an e-mail account that he or she can access through the community intranet. Conectha aimed e-mail as one of the forms of contact between Real del Sol and the residents, and among the residents. No additional accounts are provided to other residents in the same household.

Real del Sol's intranet services are only accessible to residents of the development through a personal account and password. Through a simplified menu, users can select different services including access to security cameras, community information, contract information, educational content, on-line ordering of grocery and other products. Beyond these local services, the intranet provides links to external sources such as job banks, adult education, and entertainment. 


\subsection{Security Cameras System}

With a rampant increment in the number of kidnappings, burglaries and other forms of crime in the urban Mexican neighborhoods, having safe and secure housing environments is a priority for most people. Attending that need, the developers installed a set of video cameras all over the complex. Through the cameras, residents are able to monitor the activity outside their properties as well as four communal areas.
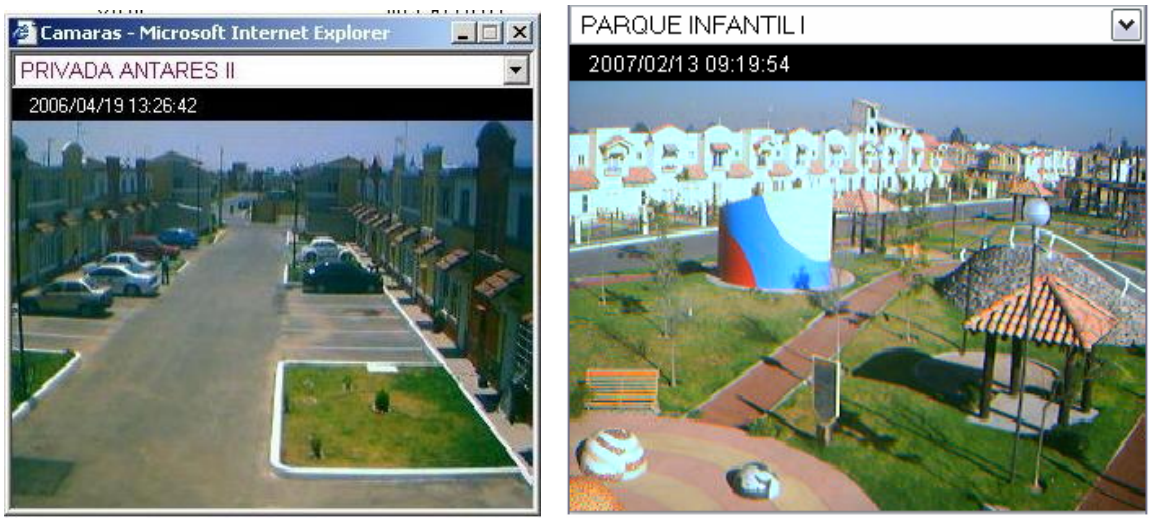

Fig. 3. Images from cameras in Real del Sol community intranet

Each privada has one camera placed at the rear of the parking lot to maximize the visual field captured. Through the community intranet, a resident can have access to the cameras which captures color images in real time. The frame rate is not fast enough to perceive sudden movements of people, but it is still useful to monitor activity. Cameras operate 24/7 and are not monitored by professional security staff. Because its web-interface, cameras can be monitored by people from anywhere, including their workplaces.

\subsection{Shopping Portal and Discount Traders}

The community intranet provides two main commercial services: online shopping and discount traders. A number of small local companies in the communities of Tecamac and Ojo de Agua, including a pharmacy, butchery, and a convenience store established a contract with Conectha to provide the services to the residents of Real del Sol through the intranet. Each business was given a computer and wireless connection to Conectha network that they use to update their product stock, receive and process orders. Figure 4 shows the interface of the shopping portal used by residents to order products from the convenience store. As opposed to other scenarios where transactions are done with credit or debit cards, the transactions in Real de Sol are in cash. People order their products online and then the shop delivers the goods by bike or motorbike and charges the costumer in cash at their door. 


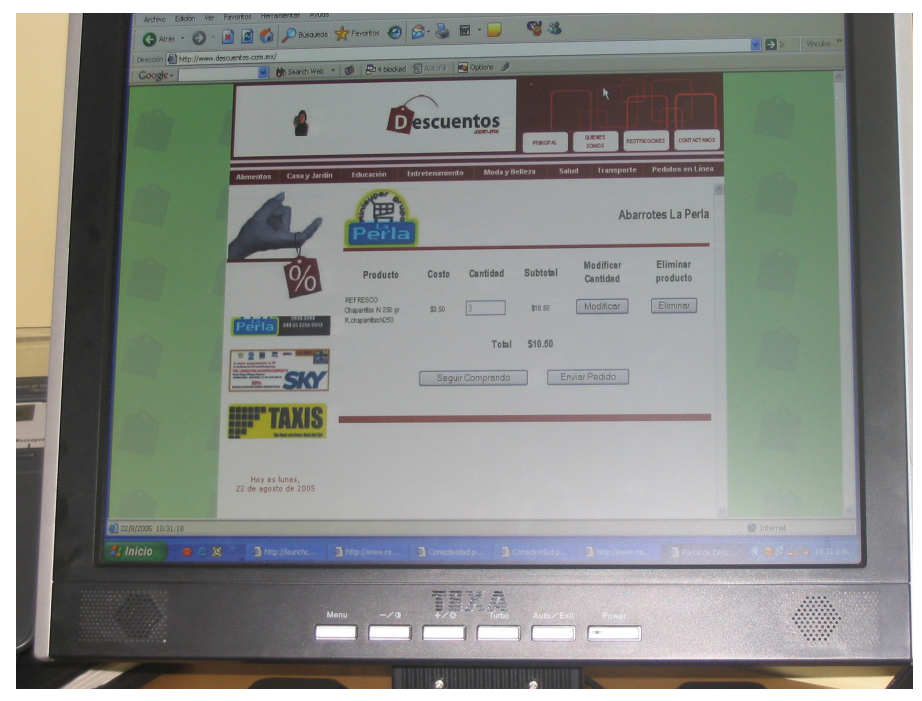

Fig. 4. The shopping portal and discount service

Many other local businesses participate in the commercial section of the intranet by providing discounts coupons to local residents. A matrix of add contains discounts from shops selling a variety of products including furniture, clothing, phone, electronics, food, baby, kitchen, and garden items. Companies advertising their coupons on the intranet, also receive advice from Conectha personnel with regards to marketing and promoting their products.

\section{Results and Findings}

Based on the analysis of our interviews and field observations, we were able to identify some aspects that are facilitating or preventing the uptake of the community intranet provide by Conectha. This section discusses the findings.

\subsection{Current Uptake of Community Intranet}

Before coming to Real del Sol, most of the interviewees had used a computer and surfed on the Web via dial-up Internet access. Consequently, for them the difference was on having internet access 24/7. With this type of access people were able to keep their computer on and do things such as having open Instant Messenger chat sessions all day, or having access to Stream Radio or similar services. Most of the informants reported using the Internet to stay in touch with family and friends, but many others also indicated they use it for work-related communications. Some self-employed informants reported that the all-day Internet service helps them to stay connected with clients or providers whenever it was necessary.

In contrast with internet usage in general, the actual reported usage of the community intranet was minimum. People did not check the content regularly, and even were unaware of some of the services provided. We found that most of them 
knew that an intranet was operating and its content was interesting and valuable, but at the same time, they did not have a motivation to regularly consult it.

In general, we can argue that people do make use of the services provided although not often with the aim they were conceived. Instead, people have tailored the services to their own needs of communication and organization. The actual usage is discussed in the following lines.

\subsection{Factors Facilitating or Preventing the Uptake of Community Intranet}

Electronic communication was a service that most informants identified as a benefit of having Internet at home, but not necessarily associated as one of the services that make use through the community intranet. Given the limitation of space in the e-mail account provided by Conectha, and the availability of free services such as Yahoo or MSN, people were eventually abandoning the usage of Conectha e-mail account. Furthermore, the e-mail account was often left aside to post messages to the community as users perceived their neighbors as not regular users of the service. Interestingly, when informants were requested their contact information they provided e-mail addresses different to the ones provided by Conectha. These findings indicate that despite that e-mail might be a commodity that could be included as part of the Intranet services, the current pervasiveness of e-mail usage makes very unlikely that people will switch to use it as there are plenty of strong alternatives to compete with.

We also found that security cameras experienced a reduced usage, and when used they were not used as originally envisioned by designers. Residents were able to watch their properties while away and mainly before moving in. Because many of the future residents were provided with access to surveillance video cameras before moving in they were enabled to follow up the erection of the house as the construction moved on. Some of them, after moving in, were using the cameras not only to 'keep an eye' on their home but also for showing their homes off to their relatives and friends. The lack of usage as security tools could be mainly due because of the limited functionality of the cameras and they did not record any activity. Furthermore, people realized that no professional security staff was monitoring the cameras and even if they decided to monitor them by themselves, the level of detail and quality of the image was not optimal. Because no video-recording was done, the possibility of analysis in case of robberies was eliminated.

In contrast, the local shopping service as simple as it might seem was very adequate to the needs of people. Through the commercial link informants reported to have brought products form a local pharmacy, and a small convenience store. This service was particularly relevant and useful during the initial stage when families were settling in because they did not know what other alternatives were around and did not have time to look for them. However, once they became familiar with the area, the usage of online shopping and some discount coupons declined.

\subsection{Expected Evolution of Domestication of Community Intranet}

The domestication of the community intranet by February 2006 was clearly scarce among neighbors. However, it does not mean that the service is not working. It is working, but in a different way that expected by designers. Based on our interviews 
we can anticipate some changes will occur with the community intranet that can produce a higher level of domestication. Our study revealed that some distinction has to be made between those services that can be beneficial during the process of moving in and those that people will use once they settle in. Consequently, we expect more of the latter services being created and adopted. People mentioned some services that could be valuable at the latter stage, among them medical services, stationery stores and an eBay-like web site to enable neighbors to sale used items among them. Some neighbors expressed plans to start the latter service, and personnel from Conectha mentioned similar idea.

Given the concerns with regards security it is likely that this need will be attended either through cooperation among neighbors or as a service from Conectha. Some neighbors expressed that they will contract more and better security cameras from Conectha. Some other are planning to install alarms and other security devices in their privada. The relevance of this aspect is likely to place a major role on communication and organization among neighbors.

We found that the needs of communication among neighbors could be fulfilled in a better way. Given the scarce use of Conectha e-mail account, the lack of awareness regarding the e-mail addresses of their neighbors, and the fact that not everybody even owns a computer, residents have fulfilled their communication needs with pieces of paper posted on the houses' front doors and public places such as the school. Some reported that they were planning to collect e-mail addresses and eventually, once enough critical mass is reached, we can expect that e-mail will be more relevant for communication among residents. Conectha, has also discussed ideas with regards encouraging the use of the Web site as an electronic posting service together with a public display such as the ones used in most banks (i.e. led-based displays).

Overall, we believe that lacking full participation in the content creation of the community intranet is preventing its adoption by residents. This situation is likely to change as Conectha is planning modification to the intranet that would make possible that scenario.

\section{Conclusions}

We present results from a study of an implementation of habitat computing in Mexico and focus on the analysis of the community intranet uptake. A main conclusion of our study is that further attention has to be placed on the changing nature of the needs regarding community intranet usage. We showed how some needs are more relevant at certain times, which demands from designers to provide adaptive applications. The findings indicate that the adoption of the community intranet is still minimal among residents, however we believe that based on the plans of Conectha and those of the residents, the domestication of the intranet will more palpable in the near future.

Acknowledgments. We wish to express our gratitude to all families in Real del Sol participating in our study as well as to the people of Real Paraiso Residencial and Conectha for their support. This study was made possible by a grant from The University of California Institute for Mexico and the United States (UC MEXUS). 


\section{References}

1. AMIPCI (2005) Hábitos de los Usuarios de Internet en México 2005 (October 2005)

2. INEGI (2005) Encuesta Nacional sobre Disponibilidad y Uso de Tecnologías de la Información en los Hogares (November 2005)

3. Kraut, R.E., Brynin, M., Kiesler, S.: Computers, Phones, and the Internet: Domesticating Information Technology. Oxford University Press, NY (2006)

4. Carroll, J., Rosson, M.: Developing the Blacksburg Electronic Village. Communications of the ACM 39(12), 69-74 (1996)

5. Venkatesh, A., Stolzoff, N., Shih, E., Mazumdar, S.: The Home of the Future: An Ethnographic Study of New Information Technologies in the Home. Advances in Consumer Research XXVIII, Valdosta, Georgia: Association for Consumer Research, 2001, pp. 88-96 (2001)

6. Foth, M., Brereton, M.: Enabling local interaction and personalized networking in residential communities through action research and participatory design. In: Hyland, P., Vrazilic, L. (eds.) Proceeding of OZCHI 2004: NSW: University of Wollongong (2004)

7. Pinkett, R.: Community Technology and Community Building: Early Results form the Creating Community Connections Project. The. Information Society 19(5), 365-379 (2003)

8. Foth, M.: Analyzing the factors influencing the successful design and uptake of interactive systems to support social networks in urban neighborhoods. International Journal of Technology and Human Interaction, 2(2) (2006)

9. Gurstein, M.: Community informatics, community networks and strategies for flexible networking. In: Keeble, L., Loader, B.D. (eds.) Community informatics: Shaping Computer-Mediated Social Relations, pp. 263-283. Routledge, New York (2001)

10. Venkatesh, A., Chen, S., Gonzalez, V.: A Study of a Southern California Wired Community: Where Technology Meets Social Utopianism. In: Proceedings of HumanComputer Interaction 10th International Conference, June 22-27, 2003 Crete, Greece (2003) 